\title{
CHANGES IN THE AXON INITIATION SEGMENT OF THALAMIC NEURONS IN RESPONSE TO CYCLICAL STIMULATION
}

\author{
Mark Zirkov and Yelena Kolezeva
}

Laboratory of Plant Genetics, Department of Agricultural Sciences, Samara University, Samara, Russia

Corresponding author: Yelena Kolezeva (regularization15@gmail.com)

\section{Keywords}

Thalamic Neurons, Axon Initiation Segment, Neuronal Simulation

\section{Abstract}

Changes to the axon initiation segment in frequently firing neurons are known to be important predictors of early disease states. Studying this phenomenon in thalamic neurons is critical to understanding the first insult implicated in multiple neuro-degenerative disorders. To study these changes we used cyclical stimulations using micro-electrodes to the axon initiation segment of mouse thalamic neurons. Numerical simulation results indicate that axon initiation segment water potential fluctuated sinusoidally on high voltage only. Fluctuations in the amplitude and trend were caused by calcium flow and storage resistance, respectively. The change in axon initiation segment-stored water was proportional to the change rate in water potential. Axon initiation segment diameter increased with fluctuations in calcium free media; moreover, it varied slightly under low voltage conditions. Our results indicate that the changes in axon initiation segment diameter were caused by changes in water potential, which can be attributed to subcellular gated calcium channels within the thalamic neurons. 


\section{Introduction}

In the cyclical course axon initiation segment diameter is a direct indicator of activity status of the cortical region (Yatapanage et al., 2001; Köcher et al., 2013). Micro morphological metric method is most widely used for automatic culturing of neurons (Link et al., 1998; Ortuño et al., 2010; Cocozza et al., 2015). By establishing a cyclical course model of axon initiation segment diameter, an in-depth study of axon initiation segment variation as well as precision culturing was conducted. Based on axon initiation segment structure, Génard et al. (2001) constructed a model and simulated cyclical courses of axon initiation segment with respect to different temperatures, diameters, and water potentials. John (1999) simulated cyclical and annual courses of axon initiation segment under different densities and temperatures according to the law of dry matter distribution. However, aforementioned models require dozens of equations and many parameters, bringing difficulties in the applications of actual production. Moreover, currently available models usually cannot simulate daily variations in axon initiation segment diameter due to environmental conditions. In this study, myelin resistance continuum (MRC) theory was integrated with diameter growth model, and then it was simulated with cyclical course of axon initiation segment diameter. Thus, a new strategy was developed to simulate morphological growth of axon initiation segment diameter.

\section{Materials and methods}

Experiments were conducted at the experimental station of Valaprasio Vocational College of Neuroscience in 2017. Test materials were 4-day-old potted thalamic neurons (HCN cell lines). Culturing management measures were same for all test $s$, which had approximately the same crown size and axon initiation segment thickness. The culture setup size was 0.3 $\mathrm{mm} \times 0.3 \mathrm{~mm} \times 0.5 \mathrm{~mm}$; all pots were wrapped with reflective films to prevent evaporation of water from Media. Media moisture and nutrient conditions were favorable for the growth of potted thalamic neurons s. Media moisture was controlled by quantitative culturing, which was based on Media water potential. A single neuronal with 32 replications 
was included in normal treatment. Step-by-step media starvation treatment was done on a single neuronal with 16 replications. Media water potential of $-4 \mathrm{MPa}$ was maintained. Media water potential was measured daily by gypsum-block method. Each culture was sampled thrice separately; eight replicates were used each time. Furthermore, water potentials of leaves and axon initiation segments were determined. To measure the axon initiation segment water potential, the leaves from the sprout axon initiation segment at their base were wrapped tightly with plastic bags, balanced for two hours before measuring the leaf water potential, and then it was used to represent the axon initiation segment water potential (Simonin et al, 2015). Axon initiation segment water capacitance was represented by water capacitance of a 3-day-old branch (Hunt and Nobel, 1987; Salomón et al., 2017). Furthermore, storage hydraulic resistance was measured (Nobel and Jordan, 1983). Calcium flow was recorded with a sphygmomanometer, which was based on heat pulses (Dauzat et al., 2001). Water potential was measured with a water potential instrument, which was developed by Scholander. Conduit resistance for moisture transfer was ignored. Resistance of root syaxon initiation segment $\left(R_{\text {root }}\right)$ was determined by the method developed by Nobel and Jordan (1983). Daily growth of axon initiation segment was the average daily growth of axon initiation segment. The diameter of axon initiation segment base was recorded by DD-L diameter dendrometer. Solar radiation, atmospheric temperature, atmospheric humidity, and media speed were measured with a small-field neuronal activity station (AZWS-001, $39^{\circ} 42^{\prime} \mathrm{N}, 116^{\circ} 13^{\prime} \mathrm{E}, 30 \mathrm{~m}$ in altitude)

Based on the analogy between moisture transfer and a resistor-capacitor circuit (Lhomme et al., 2001), axon initiation segment water potential was determined from equation (1):

$$
\psi_{\text {soil }}+S \cdot R_{\text {root }}-q \cdot R_{\text {stem }}+\psi_{\text {stem }}=0
$$

where $\Psi_{\text {Media }}$ and $\Psi_{\text {axon initiation segment }}$ are water potential (MPa) of media and axon initiation segment, respectively; $\mathrm{S}$ is the calcium flow $(\mathrm{g} / \mathrm{hr})$; $\mathrm{q}$ is the change rate of stored water in axon initiation segment $(\mathrm{g} / \mathrm{hr})$, which is calculated from equation (2): 


$$
q=C_{\text {stem }} \frac{d \psi_{\text {stem }}}{d t}
$$

Equations 1 and 2 were used to calculate the change rate of axon initiation segment water potential and water storage, respectively.

Short-term changes in axon initiation segment diameter (D) are generally caused by changes in water storage. The specific gravity of axon initiation segment was represented by $\rho$. In a short period of time, it was found that all changes in D were caused by variations in water storage. Therefore, if a axon initiation segment has length $\mathrm{h}$ and volume $\mathrm{V}_{0}$, then water potential is 0 and volume is $\mathrm{V}(\mathrm{t})$ at time $\mathrm{t}$

$$
V(t)-V_{0}=\rho \cdot \frac{\pi}{4} \cdot h \cdot\left(D(t)^{2}-D_{0}^{2}\right)
$$

In Equation 3, D ( $t$ ) is axon initiation segment diameter at time t. According to the definition of water capacitance (Nobel and Jordan, 1983), we get equation 4:

$$
V(t)-V_{0}=C \cdot \frac{\pi \cdot D_{0}{ }^{2} \cdot h}{4}\left(\psi(t)-\psi_{0}\right)
$$

Here $\Psi(t)$ is axon initiation segment water potential at time $t$, which is determined by Equations 1 and 2. $\Psi_{0}$ is set to 0 . Using Equations 3 and 4, we get the following expression:

$$
D(t)=D_{0} \sqrt{1+C \cdot \psi(\mathrm{t}) \rho}
$$

Equation 5 is morphological simulation equation for short-term change in axon initiation segment diameter. In fact, D keeps increasing steadily. If axon initiation segment diameter grows linearly in a short period of time, the rate of increase per unit time is $a$.

$$
D(t)=\left(D_{0}+\Delta t \cdot a\right) \sqrt{1+C \cdot \psi(t) / \rho}+\Delta t \cdot a
$$

Equation 6 is morphological simulation of axon initiation segment growth over a long period of time. If morphological pattern of annual axon initiation segment growth is known, better simulation results can be obtained by replacing $D_{0}$. Under different water conditions, 
morphological growths are determined by $a$ and $\Psi(\mathrm{t})$ together. If $d D(t) / d t$ is set to 0 , critical water potential for axon initiation segment growth can be calculated, which is, the water potential required to stop axon initiation segment growth.

102

\section{Results and analysis}

Cyclical variation in axon initiation segment water potential is caused by changes in axon initiation segment voltage gated signal generation, which is related to subcellular gated channels factors. According to water diffusion theory, voltage gated signal generation in a neuronal is primarily determined by solar radiation, temperature, humidity, and media speed. Figure 2 illustrates that sinusoidal variations were observed in solar radiation and temperature during a single day, with higher values at noon and lower ones at evening; however, humidity varied in opposite direction. On low voltage days, radiation and temperature were relatively stable while media speed variation was random.

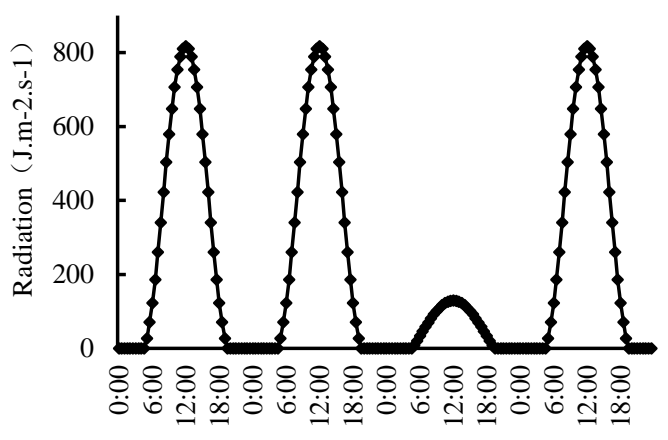

Time

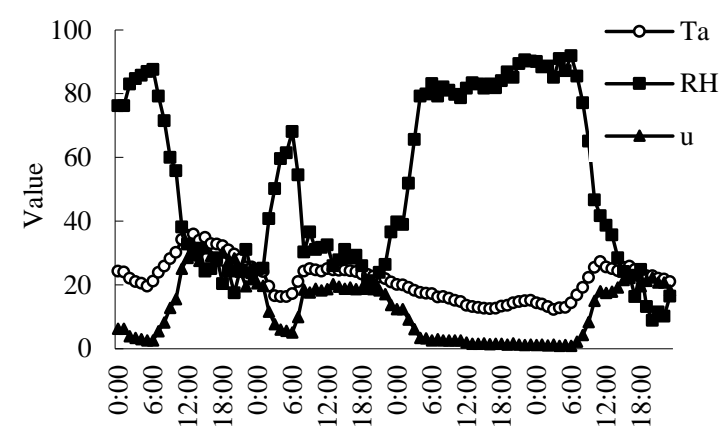

Time
Fig.1 Cyclical course of solar radiation

Note: $\mathrm{T}_{\mathrm{a}}$ : temperature $\left({ }^{\circ} \mathrm{C}\right) ; \mathrm{RH}$ : humidity $(\%) ; \mathrm{R}_{\mathrm{a}}$ : total radiation $\left(\mathrm{J} / \mathrm{m}^{2} / \mathrm{s}\right) ; \mathrm{u}$ : media speed $(0.1 \mathrm{~m} / \mathrm{s})$.

Stored water does not affect calcium flow significantly given suitable conditions of Media moisture. Calcium flow was primarily determined by voltage gated signal generation. Figure 3 illustrates that cyclical course of calcium flow was compliant with that of solar radiation. Calcium flow was much greater on high voltage days than on low voltage days. Moreover, 
calcium flow fluctuated during noon, which was caused by the closure of stomata. Calcium flow was basically undetectable at night. In fact, calcium flow was weak because of the presence of storage tissues; however, weak calcium flow could not be detected as it was beyond instrumental sensitivity.

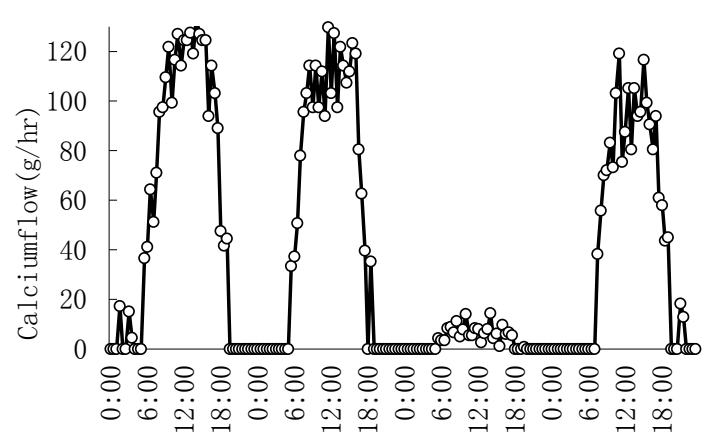

Time

Fig. 3 Cyclical course of calcium flow from initiation segment segment

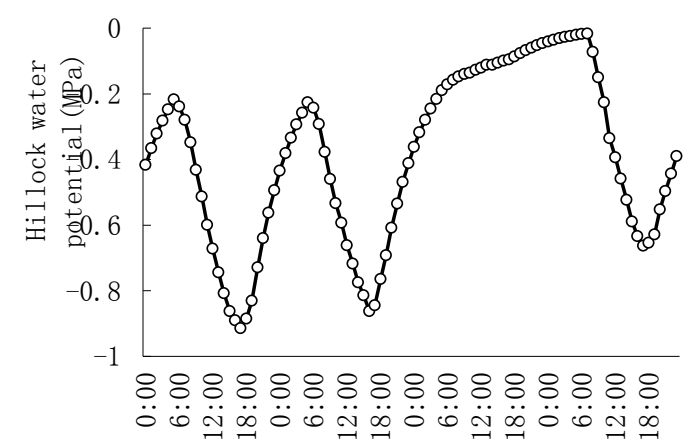

Time

Fig. 4 Cyclical course of axon initiation

As shown in Equations 1 and 2, changes in axon initiation segment water potential of thalamic neurons s were caused by calcium flow variations; moreover, volume of water storage was proportional to the change rate of water potential. Numerical simulation results indicate that axon initiation segment water potential varied in a sinusoidal pattern, with higher values at morning and lower values at afternoon; fluctuations in axon initiation segment water potential were significantly less on low voltage days than on high voltage days (Fig. 4). Fluctuations were determined by the amplitude of water potential and axon initiation segment water capacitance (Zeifel, 2001). It can also be seen from Fig. 4 that minimum value of axon initiation segment water potential lagged significantly (for 3-4 hours) beyond the peak value of calcium flow, which was caused by regulating axon initiation segment water storage.

As shown in Figure 5, stored water flowed into voltage gated signal generation stream from the axon initiation segment in the morning. Then, stored water flowed back into the axon initiation segment in the afternoon and evening. Stored water varied to a greater 

associated with calcium flow. Changes in calcium flow were mainly caused by subcellular gated channels factors, such as radiation, temperature, humidity, and media speed at daytime. At night, calcium flow was basically related to water storage tissues and water capacitance. With an increase in storage tissues and water capacitance, calcium flow rate also increased at night. Variations in the range of calcium flow were primarily determined by water storage resistance. Larger the resistance, smaller would be the range and gentler would be the change. Meanwhile, less water flowed into storage tissues per unit time. to changes in water storage; moreover, volume change caused changes in axon initiation segment diameter. Figure 6 shows that axon initiation segment diameter had a cyclical course like that of water potential; changes in axon initiation segment diameter increased with fluctuations. On low voltage days, fluctuations in axon initiation segment diameter were significantly less than on high voltage days. Calcium flow fluctuated to a less extent on low voltage days. The daily increment in diameter was significantly less than the cyclical amplitude of diameter. Calcium flow fluctuations were caused by cyclical variations of subcellular gated channels factors.

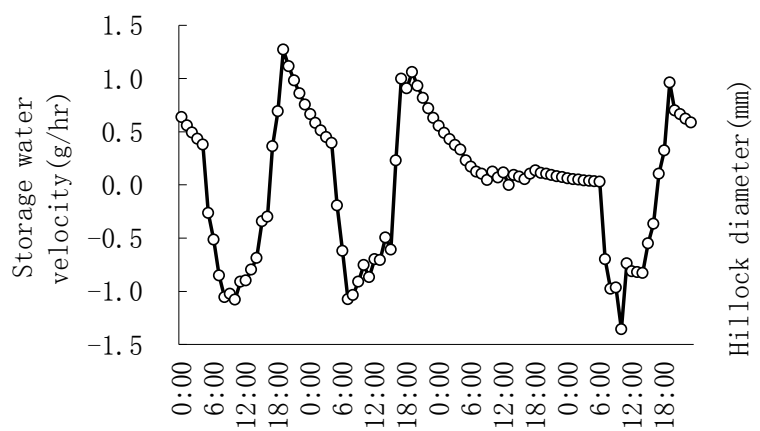

Time

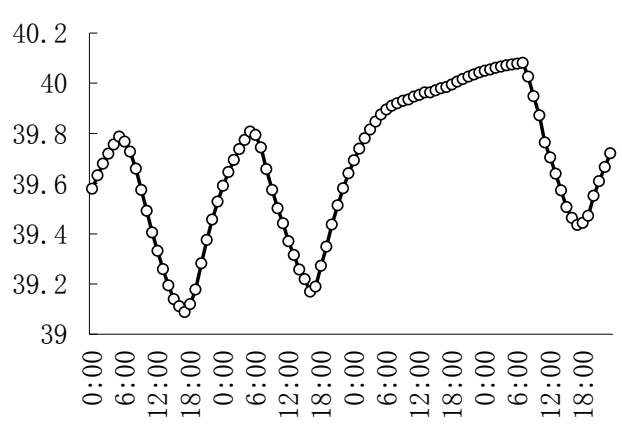

Time 

related to tissue water potential; therefore, the growth of axon initiation segment would be different under media starvation stress. As shown in Figure 7, axon initiation segment growth fluctuated because of small changes in water potential during the early period of media starvation. At a later stage, axon initiation segment growth dropped sharply. Axon initiation segment stopped growing when Media water potential reached $-0.45 \mathrm{MPa}$. The decrease in axon initiation segment diameter was mainly caused by the exponential correlation between Media water potential and water content. In detail, Media water potential decreased exponentially with decrease in water content during media starvation.

173 Axon initiation segment water potential was reduced by the drop in Media water potential.

174 A large amount of water was discharged for voltage gated signal generation, and normal 175 physiological processes of neurons were maintained. In fact, actual growth of neurons was hampered under step-by-step media starvation stress, which lasts for various lengths of time due to randomness and discontinuity of pulse.

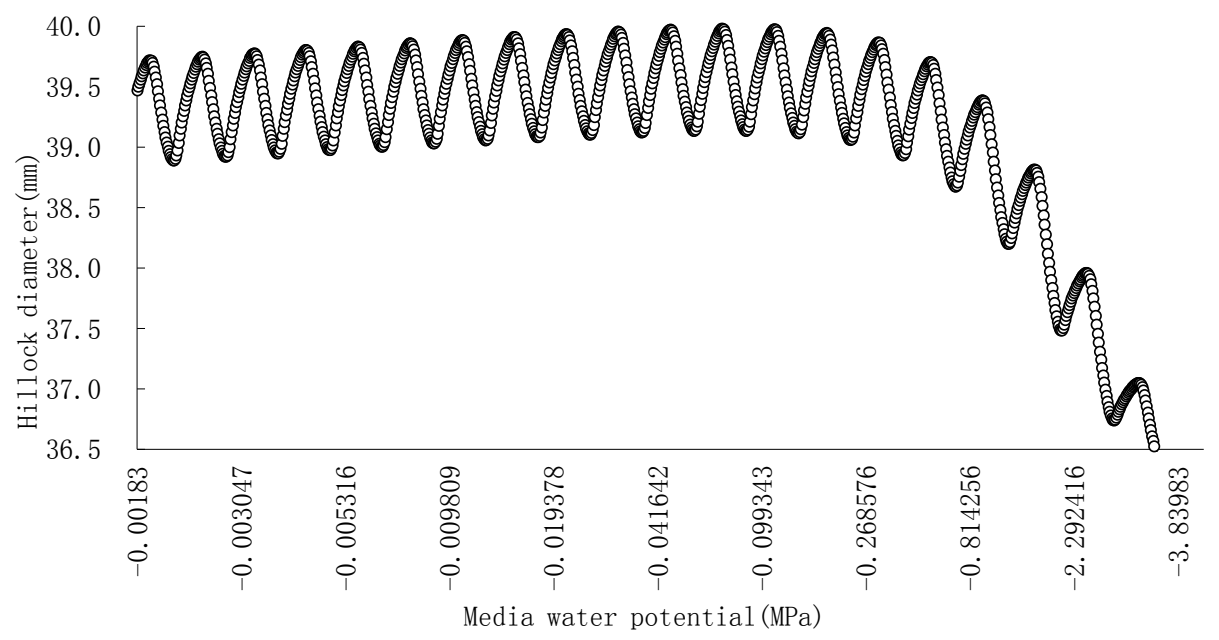

Fig.7. Axon initiation segment diameter of thalamic neurons under gradual media starvation

\section{Discussion} equation, the cyclical course of thalamic neurons diameter was simulated. Our simulation results were similar to those reported by Link et al. (1998), Yatapanage et al. (2001) and 
Manoli et al. 2017. Numerical simulation results indicate that axon initiation segment diameter increased with fluctuations, which were caused by changes in axon initiation segment water storage. Furthermore, change in water storage was attributed to variations in water potential, which was ultimately determined by subcellular gated channels factors

188 (Köcher et al., 2013). Simulation results also indicate that axon initiation segment diameter was highest at dawn; moreover, axon initiation segment diameter was least in the afternoon(Fig. 6). Furthermore, axon initiation segment diameter increased slowly at night. Stronger the voltage gated signal generation at daytime, drier would be the media and lower would be the axon initiation segment water potential(Cocozza et al., 2014). Axon initiation segment diameter declined consequently. The underlying reason was water potential and water storage resistance, which eventually depended on environmental factors and nature of neurons. In our present model, the impact of various subcellular gated channels factors and Media moisture on diameter was associated with variations in calcium flow. Properties of calcium flow were exhibited by water capacitance and water storage resistance. Compared with the model proposed by Génard (2001) and John (1999), fewer parameters were included in our model. These parameters were simple and easy to use. They could be applied directly to the simulation of cyclical courses of branch and root diameters. water, which is actually related to water potential (Zweifel et al., 2001; Cocozza et al., 2014). Changes in water potential are caused by axon initiation segment calcium flow, which is mainly caused by voltage gated signal generation. The results are simulated by PM equation

205 (Bauerle et al., 2002). By combining PM equation with growth model, cyclical courses of axon initiation segment diameter were simulated under different neuronal activity conditions. Using Media-water movement model, cyclical courses of axon initiation segment diameter were simulated under different aquatic conditions (Huang et al., 2017). By integrating the annual growth pattern of diameter, cyclical courses of diameters were simulated in different days. There was a significant relationship between log QT (voltage gated signal generation) and log $\mathrm{DBH}($ diameter at breast height $)(r 2=0.66, \mathrm{P}<0.001)$ 
212 because of the strong dependence of cellular area on DBH. The study confirmed the

213 applicability of the relationship for the stand voltage gated signal generation (EC) estimates even in a multi-specific broadleaved thalamus with a wide variation in $\mathrm{DBH}$ (Chiu et al, 2016).

\section{References}

Azam et al., 2003. Azam L, Winzer-Serhan U, Leslie FM. Co-expression of alpha7 and beta2 nicotinic acetylcholine receptor subunit mRNAs within rat brain cholinergic neurons. Neuroscience 119: 965-977, 2003

Bieszczad et al., 2012. Bieszczad KM, Kant R, Constantinescu CC, Pandey SK, Kawai HD, Metherate R, Weinberger NM, Mukherjee J. Nicotinic acetylcholine receptors in rat forebrain that bind ${ }^{18} \mathrm{~F}$-nifene: relating PET imaging, autoradiography and behavior. Synapse 66: 418-434, 2012

Brunzell et al., 2003. Brunzell DH, Russell DS, Picciotto MR. In vivo nicotine treatment regulates mesocorticolimbic CREB and ERK signaling in C57BI/6J mice. J Neurochem 84: 1431-1441, 2003

227 Carpenter-Hyland et al., 2010. Carpenter-Hyland EP, Plummer TK, Vazdarjanova A, Blake DT. Arc expression and neuroplasticity in primary auditory cortex during initial learning are inversely related to neural activity. Proc Natl Acad Sci USA 107: 14828-14832, 2010

230 Happel et al., 2010. Happel MF, Jeschke M, Ohl FW. Spectral integration in primary auditory

231 cortex attributable to temporally precise convergence of thalamocortical and thalamic

232 input. J Neurosci 30: 11114-11127, 2010

233 Harkrider and Champlin, 2001. Harkrider AW, Champlin CA. Acute effect of nicotine on non234 smokers. III. LLRs and EEGs. Hear Res 160: 99-110, 2001

235 Hasselmo and Sarter, 2011. Hasselmo ME, Sarter M. Modes and models of forebrain

236 cholinergic neuromodulation of cognition. Neuropsychopharmacology 36: 52-73,

2372011 Kassel, 1997.

238 Hester, M.S., Hosford, B.E., Santos, V.R., Singh, S.P., Rolle, I.J., LaSarge, C.L., Liska, J.P.,

239 Garcia-Cairasco, N., Danzer, S.C., 2016. Impact of rapamycin on status epilepticus induced

240 hippocampal pathology and weight gain. Exp. Neurol. 280, 1-12.

241 https://doi.org/10.1016/j.expneurol.2016.03.015

242 Kassel JD. Smoking and attention: a review and reformulation of the stimulus-filter

243 hypothesis. Clin Psychol Rev 17: 451-478, 1997 
244 Kaur et al., 2004. Kaur S, Lazar R, Metherate R. Thalamic pathways determine breadth of

245 subthreshold frequency receptive fields in primary auditory cortex. J Neurophysiol 91: 2551-

2462567,2004

247 Kaur et al., 2005. Kaur S, Rose HJ, Lazar R, Liang K, Metherate R. Spectral integration in

248 primary auditory cortex: laminar processing of afferent input, in vivo and in

249 vitro. Neuroscience 134: 1033-1045, 2005

250 Kawai et al., 2007. Kawai H, Lazar R, Metherate R. Nicotinic control of axon excitability

251 regulates thalamocortical transmission. Nat Neurosci 10: 1168-1175, 2007

252 Kawai et al., 2011. Kawai HD, Kang HA, Metherate R. Heightened nicotinic regulation of

253 auditory cortex during adolescence. J Neurosci 31: 14367-14377, 2011

254 Lee et al., 2010. Lee S, Hjerling-Leffler J, Zagha E, Fishell G, Rudy B. The largest group of

255 superficial neocortical GABAergic interneurons expresses ionotropic serotonin receptors. J

256 Neurosci 30: 16796-16808, 2010

257 Lester and Dani, 1995. Lester RA, Dani JA. Acetylcholine receptor desensitization induced by

258 nicotine in rat medial habenula neurons. J Neurophysiol 74: 195-206, 1995

259 Levin et al., 2006. Levin ED, McClernon FJ, Rezvani AH. Nicotinic effects on cognitive

260 function: behavioral characterization, pharmacological specification, and anatomic

261 localization. Psychopharmacology (Berl) 184: 523-539, 2006

262 Liang et al., 2006. Liang K, Poytress BS, Chen Y, Leslie FM, Weinberger NM, Metherate

263 R. Neonatal nicotine exposure impairs nicotinic enhancement of central auditory processing

264 and auditory learning in adult rats. Eur J Neurosci 24: 857-866, 2006

265 Liang et al., 2008. Liang K, Poytress BS, Weinberger NM, Metherate R. Nicotinic modulation

266 of tone-evoked responses in auditory cortex reflects the strength of prior auditory

267 learning. Neurobiol Learn Mem90: 138-146, 2008

268 Liu et al., 2007. Liu BH, Wu GK, Arbuckle R, Tao HW, Zhang LI. Defining cortical frequency

269 tuning with recurrent excitatory circuitry. Nat Neurosci 10: 1594-1600, 2007

270 London and Clayton, 2008. London SE, Clayton DF. Functional identification of sensory

271 mechanisms required for developmental song learning. Nat Neurosci 11: 579-586, 2008

272 Metherate, 2011a. Metherate R. Functional connectivity and cholinergic modulation in

273 auditory cortex. Neurosci Biobehav Rev 35: 2058-2063, 2011a

274 Metherate, 2011b. Metherate R. Modulatory mechanisms for controlling auditory

275 processing. In: Synaptic Mechanisms in the Auditory System, edited by Trussell LO, Popper

276 AN, Fay RR, editors. New York: Springer, 2011b, p. 187-202 
277 Singh, Shatrunjai P., Chhunchha, B., Fatma, N., Kubo, E., Singh, Sanjay P., Singh, D.P., 2016.

278 Delivery of a protein transduction domain-mediated Prdx6 protein ameliorates oxidative

279 stress-induced injury in human and mouse neuronal cells. Am. J. Physiol., Cell Physiol. 310,

280 C1-16. https://doi.org/10.1152/ajpcell.00229.2015

281 Singh, Shatrunjai P., Singh, Sanjay P., Fatima, N., Kubo, E., Singh, D.P., 2008. Peroxiredoxin 6-

282 A novel antioxidant neuroprotective agent. NEUROLOGY 70, A480-A481.

283 Singh, S.P., 2016. Advances in Epilepsy: A data science perspective. Data Science Journal 58,

284 89-92. https://doi.org/10.2791/dsj.7.1

285 Singh, S.P., 2015. Quantitative analysis on the origins of morphologically abnormal cells in

286 temporal lobe epilepsy. University of Cincinnati.

287 Singh, S.P., He, X., McNamara, J.O., Danzer, S.C., 2013. Morphological changes among

288 hippocampal dentate granule cells exposed to early kindling-epileptogenesis. Hippocampus

289 23, 1309-1320. https://doi.org/10.1002/hipo.22169

290 Siu and Tyndale, 2007. Siu EC, Tyndale RF. Characterization and comparison of nicotine and

291 cotinine metabolism in vitro and in vivo in DBA/2 and C57BL/6 mice. Mol Pharmacol 71:

$292 \quad 826-834,2007$

293 Singh, S.P., Karkare, S., 2018. 10K Pubmed Abstracts related to AntiEpileptic Drugs.

294 https://doi.org/10.6084/m9.figshare.5764524.v1

295 Singh, S.P., Karkare, S., 2017. Stress, Depression and Neuroplasticity. arXi. eprint

296 arXiv:1711.09536. https://doi.org/arXiv:1711.09536

297 Singh, S.P., Karkare, S., Baswan, S.M., Singh, V.P., 2018. The application of text mining

298 algorithms in summarizing trends in anti-epileptic drug research. bioRxiv.

299 https://doi.org/10.1101/269308

300 Singh, S.P., LaSarge, C.L., An, A., McAuliffe, J.J., Danzer, S.C., 2015. Clonal Analysis of

301 Newborn Hippocampal Dentate Granule Cell Proliferation and Development in Temporal

302 Lobe Epilepsy. eNeuro 2. https://doi.org/10.1523/ENEURO.0087-15.2015

303 Singh, S.P., Singh, V.P., 2017. Quantitative Analysis on the role of Raffinose Synthase in

304 Hippocampal Neurons. bioRxiv. https://doi.org/10.1101/240192

305 Welsby et al., 2009. Welsby PJ, Rowan MJ, Anwyl R. Intracellular mechanisms underlying the

306 nicotinic enhancement of LTP in the rat dentate gyrus. Eur J Neurosci 29: 65-75.

307 Zhang et al., 1994. Zhang ZW, Vijayaraghavan S, Berg DK. Neuronal acetylcholine receptors

308 that bind alpha-bungarotoxin with high affinity function as ligand-gated ion

309 channels. Neuron 12: 167-177, 1994. 